\title{
Gas-phase pyrolysis of methyl glucosides and levoglucosan
}

\author{
Asuka Fukutome $^{1} \cdot$ Haruo Kawamoto $^{1} \cdot$ Shiro Saka $^{1}$
}

Received: 14 November 2016 / Accepted: 30 January 2017 / Published online: 9 March 2017

(C) The Japan Wood Research Society 2017

\begin{abstract}
Levoglucosan, the major intermediate in cellulose pyrolysis, is stable up to around $500^{\circ} \mathrm{C}$ in the gas phase. To study whether this stability is a characteristic property of levoglucosan, the gas-phase reactivity was compared with those of methyl $\alpha$ - and $\beta$-glucosides at $200-500^{\circ} \mathrm{C}$ (residence time $1.2-2.0 \mathrm{~s}$ ). The methyl glucosides decomposed even at 200 and $300^{\circ} \mathrm{C}$ to form levoglucosan exclusively. This selective transglycosylation was explained with a concerted mechanism. Fragmentation of the glucosides forming $\mathrm{C} 1-\mathrm{C} 3$ carbonyl compounds started at $400^{\circ} \mathrm{C}$, a temperature lower than that of levoglucosan $\left(500^{\circ} \mathrm{C}\right)$. Thus, levoglucosan is a special carbohydrate that is stable in the gas phase, and the stability is explained by the steric hindrance of the bicyclic ring. Formation of the anhydrofuranose isomer and furans was negligible from the gas-phase pyrolysis of these compounds, suggesting that these are produced mainly from the molten-phase pyrolysis. These results show the roles of gas- and molten-phase reactions during carbohydrate pyrolysis, providing insights for upgrading biomass pyrolysis/gasification processes.
\end{abstract}

Keywords Methyl glucoside $\cdot$ Levoglucosan $\cdot$ Gas-phase reactions $\cdot$ Concerted heterolysis $\cdot$ Cellulose pyrolysis

\section{Introduction}

Pyrolysis is the underlying principle of various thermochemical conversion technologies such as carbonization,

Haruo Kawamoto

kawamoto@energy.kyoto-u.ac.jp

1 Graduate School of Energy Science, Kyoto University, Yoshida-honmachi, Sakyo-ku, Kyoto 606-8501, Japan fast pyrolysis, and gasification for producing biofuels, biochemicals, and biomaterials from biomass resources. Lignocellulosic biomass is the most promising bioresource, because there is a significant amount on the earth. Understanding the chemistry involved in the lignocellulose pyrolysis provides insights into the upgrading of these conversion processes.

Cellulose, which represents $40-50 \mathrm{wt} \%$ of the chemical components of lignocellulose, is a crystalline polysaccharide that decomposes drastically around $350^{\circ} \mathrm{C}$, and a large amount of levoglucosan (1,6-anhydro- $\beta$-D-glucopyranose; LG) is produced [1, 2]. Kwon et al. [2] reported approximately $70 \mathrm{wt} \%$ of LG from the pyrolysis of microcrystalline cellulose under vacuum pyrolysis conditions. Thus, the pyrolysis behavior of LG has been studied extensively in both molten [3-7] and gas [3, 4, 8-10] phases to understand the roles of intermediates during pyrolysis and gasification of cellulosic biomass.

The pyrolytic reactivity of LG is different in the molten and gas phases $[3,9]$. As indicated in the early report of Pictet [11] in 1918, the molten LG polymerizes into polysaccharides through transglycosylation reactions at $>240^{\circ} \mathrm{C}$, which is a temperature much lower than its formation temperature (around $350^{\circ} \mathrm{C}$ ) from cellulose. Alternatively, $\mathrm{LG}$ in the gas phase is stable and starts to decompose at higher temperatures $>500^{\circ} \mathrm{C}$ (residence time $0.8-1.4 \mathrm{~s}$ ), where fragmentation reactions selectively proceed to form $\mathrm{C} 1-\mathrm{C} 3$ aldehydes/ketones and noncondensable gases without forming any coke [9]. Any aromatic compounds such as benzenes and furans [furfural and 5-hydroxymethylfurfural (5-HMF)] are not produced in the gas phase, which is explained later by the homolysis-based fragmentation occurring at high temperatures prior to the formation of benzenes and furans [12]. Because of these different reactivities in the molten and gas phases, extensive coking 
occurs only by cooling the gaseous LG produced from cellulose pyrolysis into the molten state [13].

LG and other sugar derivatives are stabilized in aprotic hydrogen-bond-acceptor solvents such as aromatic substances $[14,15]$ and polyethers $[16,17]$. From these observations, hydrogen-bond theory was proposed, in which intermolecular hydrogen bonds act as acid and base catalysts that promote pyrolytic reactions including transglycosylation in the molten phase [15-17]. The stability of LG in the gas phase can be explained with this theory, because intermolecular hydrogen bonding is normally less important in the gas phase. However, there have been no reports to clarify whether this stability is characteristic feature of LG.

Transglycosylation forming LG and polysaccharides is the most important reaction of carbohydrates in moltenphase pyrolysis [11, 18-20]. Concerted transglycosylation mechanisms have been proposed by the theoretical calculations for the gas-phase pyrolysis of methyl $\beta$-glucoside (Glc $\beta \mathrm{OMe}$ ) [21] and other carbohydrates [22-24]. Hosoya et al. [21] proposed a concerted mechanism for the gasphase conversion of Glc $\beta O M e$ into LG, in which the $\Delta G^{0 \text { ‡ }}$ value is reduced to $47.7 \mathrm{kcal} \mathrm{mol}^{-1}$. However, these reports are only based on theoretical calculations, because of the difficulty in studying only gas-phase pyrolysis of carbohydrates. Hence, the concerted transglycosylation mechanisms have not been confirmed by experimental study.

In this study, Glc $\beta \mathrm{OMe}$, methyl $\alpha$-glucoside (Glc $\alpha \mathrm{OMe}$ ), and LG were pyrolyzed only in the gas phase at 200, 300, 400 , and $500^{\circ} \mathrm{C}$ under a $\mathrm{N}_{2}$ flow (residence times ranging from 1.2 to $2.0 \mathrm{~s}$ ) to understand the reactivities of these compounds and check the adaptability of the proposed concerted mechanisms.

Fig. 1 Flow-type two-stage tubular reactor consisting of an evaporator connected to a pyrolyzer and product recovery units

\section{Experimental}

\section{Materials}

Glc $\alpha \mathrm{OMe}$, Glc $\beta \mathrm{OMe}$ (hydrated), and LG were purchased from Tokyo Chemical Industry Co. Ltd. (Tokyo, Japan), Sigma-Aldrich (St. Louis, MO, USA), and Carbosynth Limited (Compton, Berkshire, UK), respectively. Water trapped in the Glc $\beta \mathrm{OMe}$ crystals was eliminated before use by drying in an oven at $105^{\circ} \mathrm{C}$ for $1 \mathrm{~h}$, which were stored in a desiccator before use. Other chemicals were used as received without further purification.

\section{Two-stage tubular reactor}

A two-stage tubular reactor (Fig. 1), which is fully described in our previous paper [9] dealing with the gasphase pyrolysis of LG, was used and composed of two cylindrical electric furnaces (internal diameter $35 \mathrm{~mm}$, length 160 mm; Asahi Rika Seisakusho Co., Ltd., Chiba, Japan), serving as the evaporator and pyrolyzer. Each furnace included a quartz glass tube (internal diameter $15 \mathrm{~mm}$, wall thickness $1.5 \mathrm{~mm}$ ) and these tubes were connected. One end of the evaporator was attached to a nitrogen cylinder via a mass flow controller (SEC-400MK3, Horiba Ltd., Kyoto, Japan) and the other end, coming from the pyrolyzer, was connected to a gas wash bottle via a glass wool filter. A dimethyl sulfoxide (DMSO) $-d_{6}$ solution $(2.0 \mathrm{~mL})$ containing an oximation reagent $\left(\mathrm{NH}_{2} \mathrm{OH} \cdot \mathrm{HCl}\right)(20 \mathrm{mg})$ was placed in the gas wash bottle to recover the volatile products.

\section{Pyrolysis}

The procedure reported in our previous paper [9] was used by modifying the pyrolysis temperature and heating rate in the evaporator. A solution of Glc $\alpha \mathrm{OMe}$, Glc $\beta \mathrm{OMe}$, or LG $(5 \mathrm{mg})$ in methanol $(0.1 \mathrm{~mL})$ was applied to the area separated by the fringes in the evaporator tube, and the

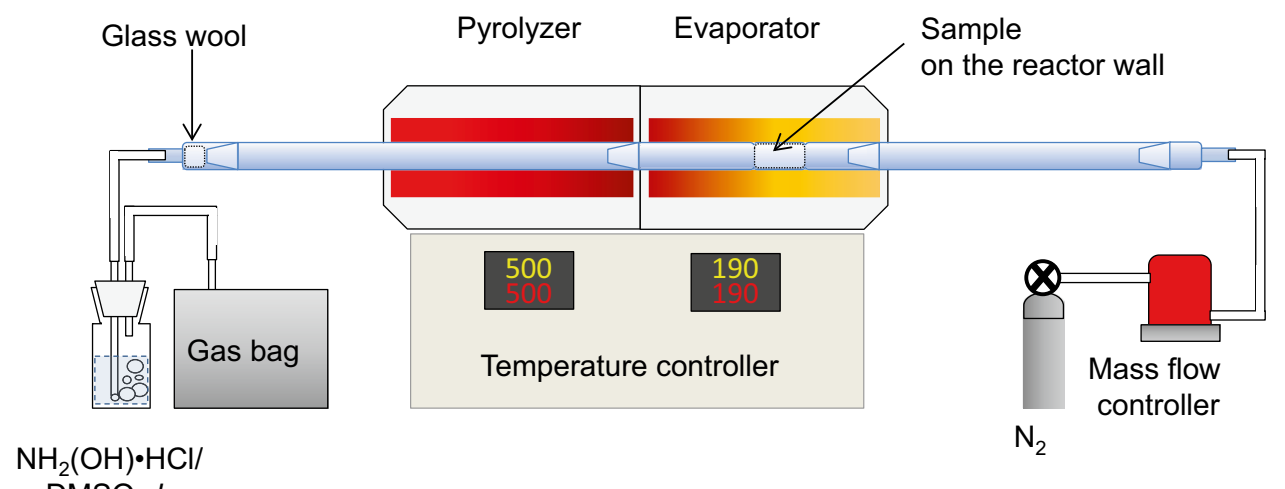


methanol was evaporated under a nitrogen flow. After the complete drying in a desiccator under vacuum, the evaporator tube was connected to the pyrolyzer tube and other components of the experimental setup, and a nitrogen flow $\left(400 \mathrm{~mL} \mathrm{~min}{ }^{-1}\right)$ was supplied for 30 min prior to conducting each pyrolysis trial to remove the air inside the reactor. The pyrolyzer was heated at the desired temperature in the range of $200-500^{\circ} \mathrm{C}$, and then, the evaporator temperature was raised to $120^{\circ} \mathrm{C}$ over $12 \mathrm{~min}$ and subsequently to $190^{\circ} \mathrm{C}$ at a heating rate of $5.8^{\circ} \mathrm{C} \mathrm{min}{ }^{-1}$. The GlcoOMe, $\mathrm{Glc} \beta \mathrm{OMe}$, and LG crystals were melt at this temperature and evaporated slowly to the volatile materials that were transported to the pyrolyzer with the flowing nitrogen. The evaporator temperature $\left(190^{\circ} \mathrm{C}\right)$ was carefully chosen to inhibit the occurrence of the molten-phase reactions. After holding the evaporator at $190^{\circ} \mathrm{C}$ for $13 \mathrm{~min}$ to complete the evaporation, heating was stopped, and the tube reactor was cooled by opening the furnace covers and subsequently applying an air flow from the outside.

By this procedure, both glucosides were evaporated prior to molten-phase pyrolysis reactions and pushed into the pyrolysis zone, where pyrolysis reactions took place. The unreacted glucosides were recovered completely on the reactor wall outlet from the pyrolyzer and in the gas wash bottle. The residence time of the pyrolyzer was defined as the period over which the gaseous substances were present in the region of the pyrolyzer with temperatures within the set value $\pm 25^{\circ} \mathrm{C}$. The residence times at 200, 300, 400 , and $500^{\circ} \mathrm{C}$ were estimated as $2.0,1.6,1.4$, and $1.2 \mathrm{~s}$, respectively.

The experiments were performed at least twice for each pyrolysis condition to confirm the reproducibility.

\section{Characterization of the pyrolysis mixture}

The condensates on the reactor tube interior wall and in the line between the reactor and the gas wash bottle were removed by rinsing with the solution in the gas wash bottle $\left(2.0 \mathrm{~mL}\right.$ of DMSO- $\left.d_{6}\right)$. The solution was analyzed directly by ${ }^{1} \mathrm{H}$ NMR spectroscopy using AC-400 (400 MHz) spectrometer (Bruker Biospin K.K., Yokohama, Japan) following the addition of 2-furoic acid as an internal standard. Quantifications of methyl glucosides, LG, and other compounds, some of which with carbonyl groups were observed as the oxime derivatives (cis/trans), were performed using the peak areas of the NMR signals compared with those of the internal standard, as described in our previous paper [9].

\section{Computational methods}

The calculations were conducted using the Gaussian 09 software package [25]. The geometry optimizations for nonradical reactants, products, and transition states (TSs) were performed by employing the density functional theory method (M06-2X) and $6-31+\mathrm{G}(\mathrm{d}, \mathrm{p})$ basis sets. For radical products, UM06-2X/6-31+G(d,p) was employed. Vibrational frequency calculations used the same methods and basis sets. The energies of optimized geometries were calculated with the same functional and 6-311+(d,p) basis set. The activation energy values and bond dissociation energies were estimated as the relative energies between the reactants and the TSs or radicals. All the energies were calculated after zero-point energy correction. Frequency analysis showed one imaginary mode for the TS and no imaginary modes for the reactants, products, and precomplexes. In addition, we performed intrinsic reaction coordinate calculations to ascertain that the TS connected the reactant and product.

\section{Results and discussion}

\section{Pyrolytic reactivity}

Figure 2 shows the recoveries of methyl glucosides and LG after pyrolysis. The gaseous LG was stable in the temperature range of $200-400^{\circ} \mathrm{C}$, whereas the methyl glucosides decomposed even at the lowest temperature of $200^{\circ} \mathrm{C}$, although the conversion rates were not large. Thus, LG is clearly more stable than methyl glucosides in the gas phase.

As indicated by the ${ }^{1} \mathrm{H}$-NMR spectra $\left(300^{\circ} \mathrm{C}\right.$, Fig. 3$)$ of the DMSO- $d_{6}$-soluble portions obtained from the pyrolysis of methyl glucosides, the major product obtained at 200 and $300^{\circ} \mathrm{C}$ was LG. The yields from Glc $\alpha \mathrm{OMe}$ and Glc $\beta O M e$ were only in the range of $3.7-14.0 \%$ (C-based),

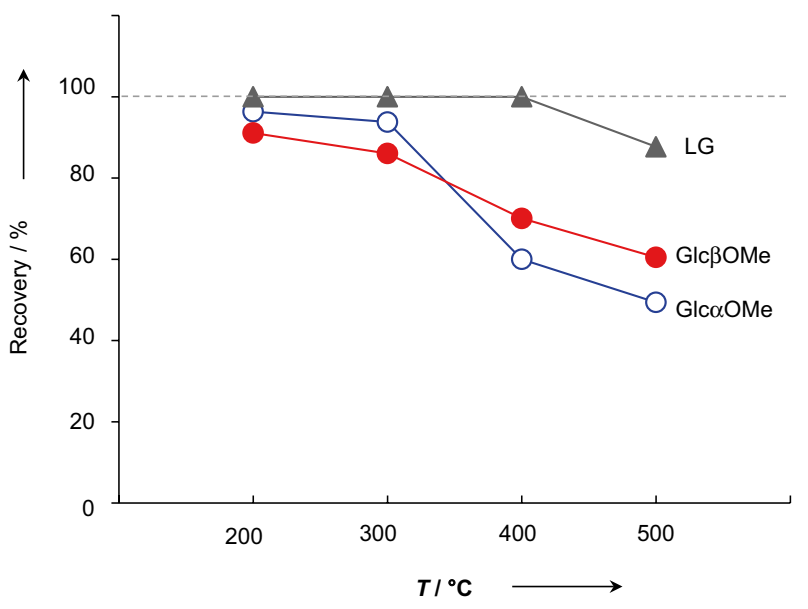

Fig. 2 Recoveries of methyl $\alpha$-glucoside, methyl $\beta$-glucoside, and levoglucosan after the pyrolysis at $200,300,400$, and $500^{\circ} \mathrm{C}$ in the gas phase (residence time $1.2-2.0 \mathrm{~s}, \mathrm{~N}_{2}$ flow $400 \mathrm{~mL} \mathrm{~min}^{-1}$ ) 
Fig. $3{ }^{1} \mathrm{H}-\mathrm{NMR}$ spectra of the DMSO- $d_{6}$-soluble portions obtained from the pyrolysis of gaseous methyl $\alpha$-glucoside (Glc $\alpha \mathrm{OMe}$ ) and methyl $\beta$-glucoside (Glc $\beta \mathrm{OMe}$ ) at $300^{\circ} \mathrm{C}$ with a residence time of $1.6 \mathrm{~s}$ under a $\mathrm{N}_{2}$ flow of $400 \mathrm{~mL} \mathrm{~min}^{-1}$. Filled squares levoglucosan (LG); open circles GlcoOMe; filled circles, Glc $\beta O M e ;$ asterisks internal standard (2-furoic acid)

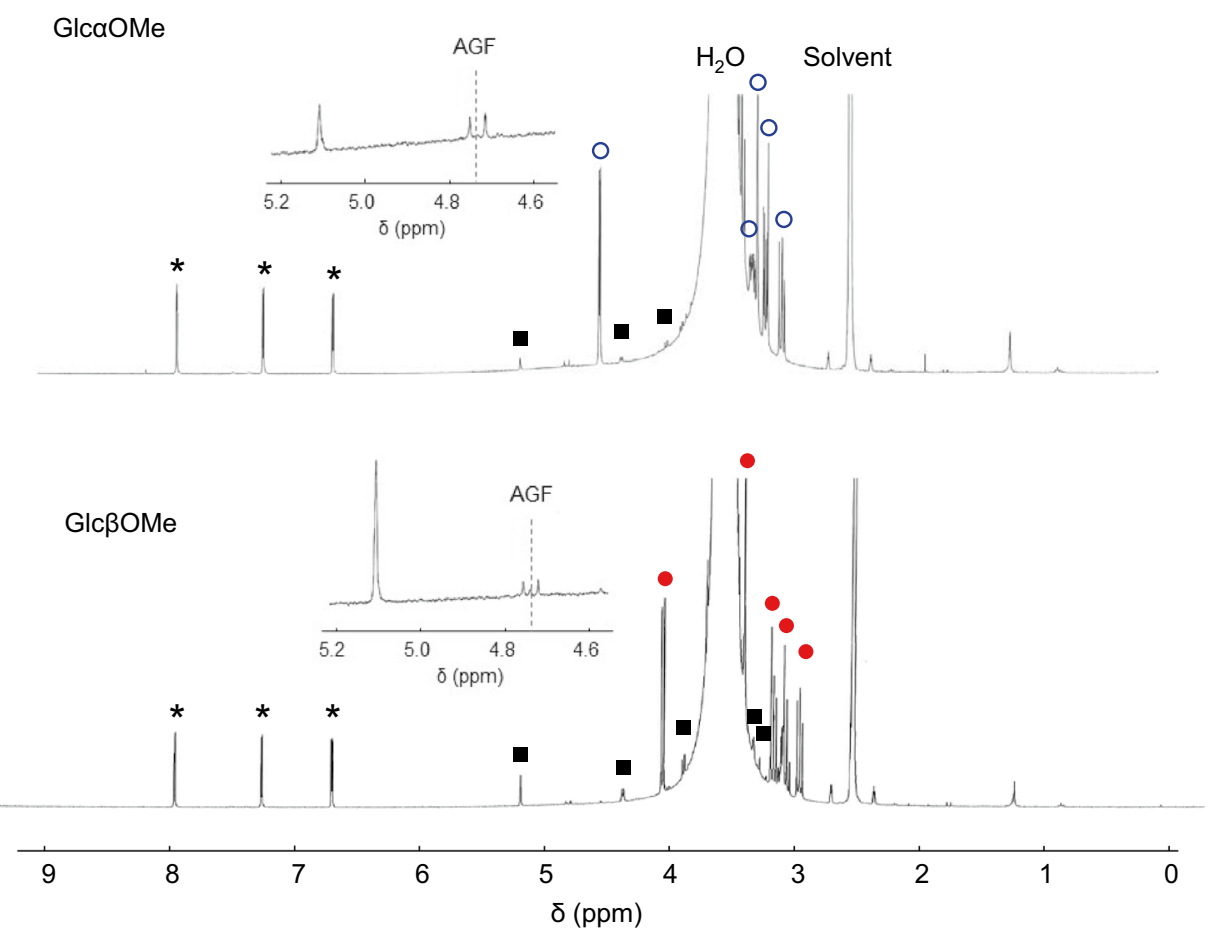

but these yields corresponded to 96.3 and $91.1 \%\left(200^{\circ} \mathrm{C}\right)$ and 93.8 and $86.0 \%\left(300^{\circ} \mathrm{C}\right)$, respectively, for the amounts of reacted glucosides. Thus, transglycosylation reactions proceeded in a low temperature range, and LG is formed selectively from the gaseous methyl glucosides. The molten Glc $\beta O M e$ were completely recovered at $200^{\circ} \mathrm{C}$ even after the $30 \mathrm{~min}$ heating under nitrogen [17], the present results of the gas-phase investigations clearly demonstrated that the transglycosylation reactivities of methyl glucosides are rather enhanced in the gas phase. This is an opposite trend to that observed for LG, which is stabilized in the gas phase.

1,6-Anhydro- $\beta$-D-glucofuranose (AGF), the furanose isomer of LG, forms along with LG from the pyrolysis of cellulose and other glucose-based carbohydrates [26-29]. Microcrystalline cellulose (Avicel PH-101) gave a mixture of LG/AGF at the molar ratio of $89 / 11$ by heating up to $500^{\circ} \mathrm{C}$ (heating rate $70^{\circ} \mathrm{C} \mathrm{min}^{-1}$ ) under a $\mathrm{N}_{2}$ flow at $400 \mathrm{~mL} \mathrm{~min}{ }^{-1}$. However, the AGF yields from the gaseous methyl glucosides were at negligible levels, as suggested by the enlarged spectra $\left(300^{\circ} \mathrm{C}\right)$ in Fig. 3, where the LG/ AGF molar ratios were calculated to be $96 / 4$ (Glc $\alpha \mathrm{OMe}$ ) and $97 / 3$ (Glc $\alpha \mathrm{OMe}$ ) from the comparison of the peak areas. These results indicate that the AGF formation proceeds mainly from the molten (liquid)-phase pyrolysis of glycosides.

By increasing the pyrolysis temperature to $400{ }^{\circ} \mathrm{C}$, fragmentation products started to be produced from the gaseous methyl glucosides. As assigned in the NMR spectrum of $\mathrm{Glc} \alpha \mathrm{OMe}$ at $500^{\circ} \mathrm{C}$ (Fig. 4), acetic acid, formic acid, and oxime derivatives (cis/trans isomers) of aldehydes were identified in the pyrolysis mixture along with LG. Only C1-C3 aldehydes were produced: $\mathrm{C} 3$ [methylglyoxal (MeGO)], C2 [glycolaldehyde (GA), glyoxal (GO), and acetaldehyde], and $\mathrm{C} 1$ [formaldehyde (FA)].

In Fig. 5, the yields of the fragmentation products are plotted against the pyrolysis temperature and compared between methyl glucosides and LG. Fragmentation reactions of LG started at $500^{\circ} \mathrm{C}$, which is higher than the onset temperature $\left(400^{\circ} \mathrm{C}\right)$ of methyl glucosides. Thus, LG is also more stable against fragmentation, and the methyl glucosides directly gave fragmentation products, not via LG, at $400{ }^{\circ} \mathrm{C}$. The major fragmentation products from methyl glucosides were MeGO, FA, GA, and GO. Noncondensable gases are also expected to form along with the condensable products by the fragmentation reactions, but any attempts to analyze the gaseous products with micro gas chromatography failed because of the low concentration by dilution with nitrogen.

Figure 6 summarizes the yields of LG (except for the case of LG pyrolysis), fragmentation products, and gas/unidentified products for each pyrolysis temperature. Methanol formed from the pyrolysis of methyl glucosides is included in gas/unidentified, because this is not the product from the fragmentation of the glucose-units of methyl glucosides. The greater stability of LG against the reactions forming these products is shown in this figure. Some different features depending on the anomer type of methyl glucosides were also identified. Transglycosylation reactivity forming LG at low pyrolysis temperatures $\left(200-400^{\circ} \mathrm{C}\right)$ was 
Fig. $4{ }^{1} \mathrm{H}-\mathrm{NMR}$ spectrum of the DMSO- $d_{6}$-soluble portion obtained from the pyrolysis of gaseous methyl $\alpha$-glucoside $(\mathrm{Glc} \alpha \mathrm{OMe})$ at $500^{\circ} \mathrm{C}$ with a residence time of $1.2 \mathrm{~s}$ under a $\mathrm{N}_{2}$ flow of $400 \mathrm{~mL} \mathrm{~min}^{-1}$. Filled squares levoglucosan (LG); open circles Glc $\alpha \mathrm{OMe}$; asterisks internal standard (2-furoic acid); acetaldehyde (AA); acetic acid $(\mathrm{AcOH})$; formaldehyde (Fald); formic acid ( $\mathrm{FcOH})$; glycolaldehyde (GA); glyoxal (GO); methylglyoxal (MeGO)
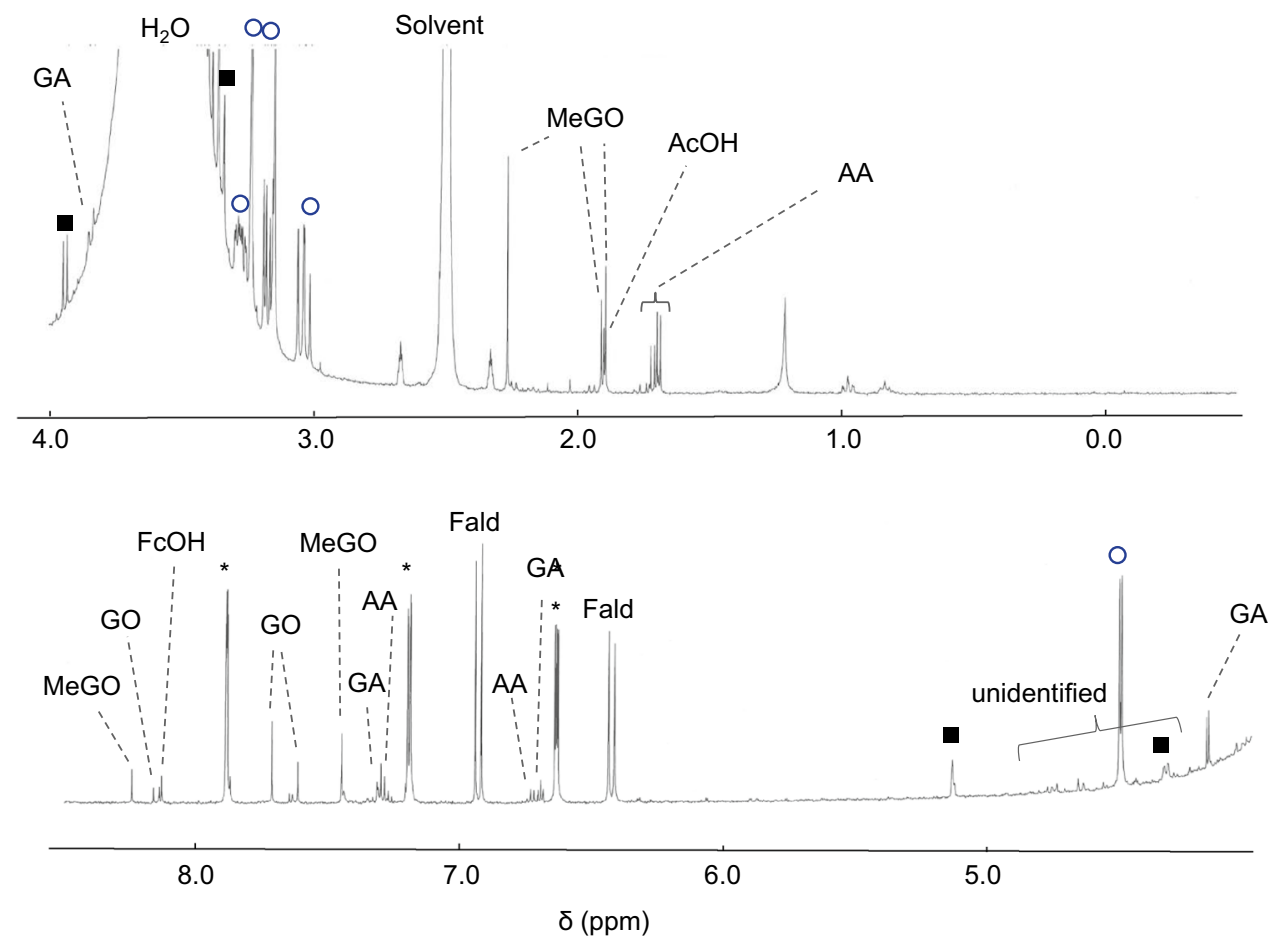

greater in the $\beta$-anomer, whereas the fragmentation reactivity that was greater at higher temperatures $\left(400-500^{\circ} \mathrm{C}\right)$ was in the opposite order $(\mathrm{Glc} \alpha \mathrm{OMe}>\mathrm{Glc} \beta \mathrm{OMe})$. These results are consistent with the temperature dependency shown in Fig. 2, where the reactivity order for Glc $\alpha \mathrm{OMe}$ and Glc $\beta \mathrm{OMe}$ is reversed in the temperature range of $300-400^{\circ} \mathrm{C}$. The greater fragmentation reactivity of Glc $\alpha \mathrm{OMe}$ can be explained with the postulated radicalchain mechanisms as discussed below.

\section{Gas-phase reaction mechanism}

\section{Transglycosylation}

Methyl glucosides produced LG at a low pyrolysis temperature of $200^{\circ} \mathrm{C}$ in the gas phase. These observations can be explained with the concerted heterolysis mechanisms as proposed by Hosoya et al. [21] for the conversion from Glc $\beta O M e$ to LG (Fig. 7). In the unimolecular mechanism, conformational change from $\mathrm{C} 1$ to $1 \mathrm{C}$ is followed by the coordination of $\mathrm{C}_{6}-\mathrm{OH}$ to $\mathrm{C}_{1}$ (glycosidic)- $\underline{\mathrm{O}}$, to form a four-membered cyclic TS, which makes the intramolecular nucleophilic substitution at $\mathrm{C} 1$ easier $\left(\Delta G^{0 \ddagger}\right.$ $47.7 \mathrm{kcal} \mathrm{mol}^{-1}$ ). They also indicated the possibility of a bimolecular mechanism, in which the association of $\mathrm{C}_{6}-\mathrm{OH}$ and $\mathrm{C}_{1}-\underline{\mathrm{O}}$ with $\mathrm{C}_{6}-\underline{\mathrm{OH}}$ of another molecule forms a more stable six-membered cyclic TS. The bimolecular mechanism reduces the $\Delta G^{0 \ddagger}$ further to $36.4 \mathrm{kcal} \mathrm{mol}^{-1}$.

No reasonable unimolecular concerted mechanisms could be proposed for Glc $\alpha \mathrm{OMe}$ because of the anomeric effect. Accordingly, selective LG formation from Glc $\alpha \mathrm{OMe}$ at such low pyrolysis temperatures could not be explained without considering the bimolecular concerted mechanisms. Although further systematic studies are necessary to conclude the involvement of the bimolecular mechanisms, bimolecular keto-enol tautomerization was proposed for the gas-phase pyrolysis of 1,3 -dihydroxyacetone at $400^{\circ} \mathrm{C}$ in our previous paper [30]. Recently, many results have been reported for the water-catalyzed gas-phase bimolecular reactions to understand the atmospheric chemistry, which reduce the energy barriers [31-34].

Bimolecular mechanism requires the association of two molecules, which is considered to be normally less effective in the gas phase, particularly under diluted conditions, due to the increasing entropy. In spite of this criterion, cluster formation in gas phase is well known for the molecules that can form hydrogen-bonded complexes, such as carboxylic acids and alcohols. For example, methanol has been reported to exist as dimers, trimers, and oligomers along with monomer in the gas phase, based on the measurement of the deviation from the ideal gas behavior, thermal conductivity, infra-red spectrum, and so on [35-45]. Furthermore, radical-molecule complexes are known to act as a prereactive complex for hydrogen abstraction by radicals such as $\cdot \mathrm{OH}$ in the gas phase [32, 33, 46, 47]. These lines of information lead to a hypothesis that some of the methyl glucoside molecules may form cluster in the gas phase, which rather reasonably explains the observation: transglycosylation of methyl glucosides occurs more efficiently in the gas 


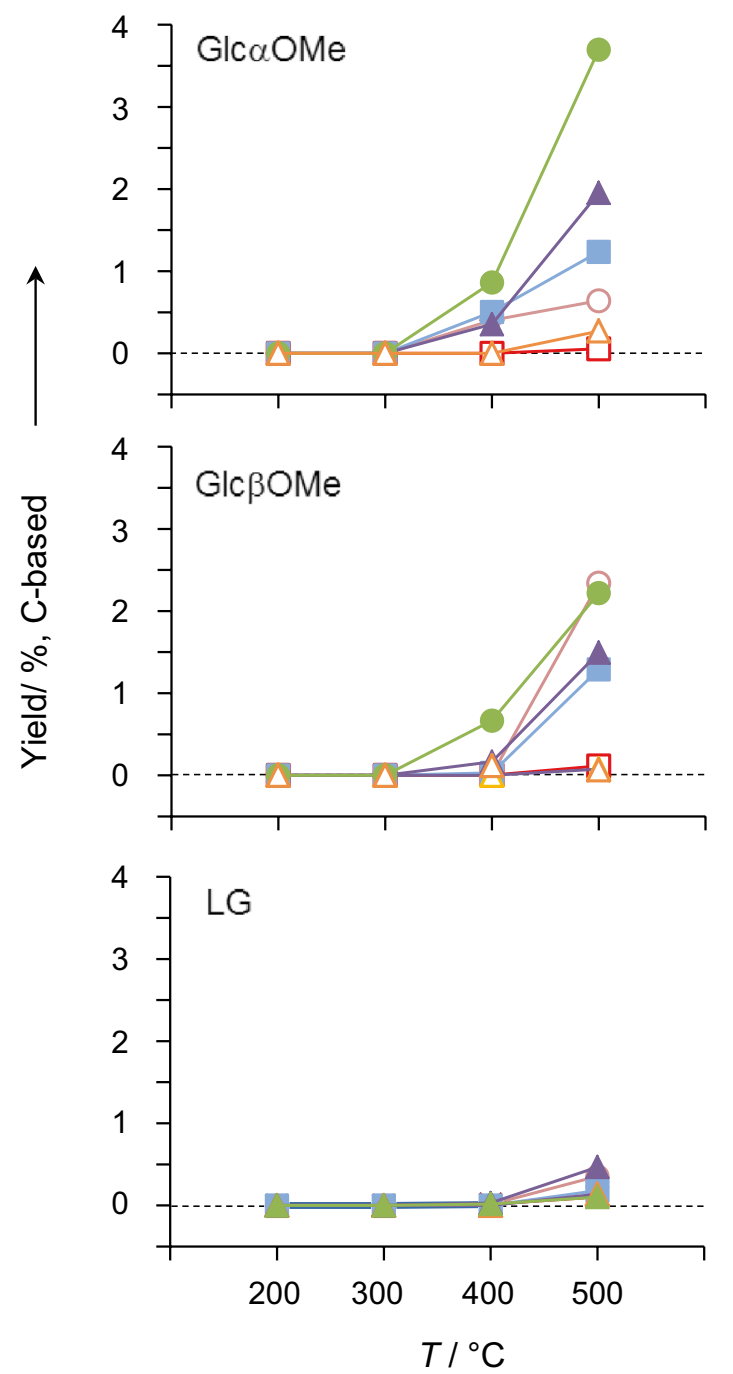

Fig. 5 Yields of fragmentation products from methyl $\alpha$-glucoside (Glc $\alpha \mathrm{OMe}$ ), methyl $\beta$-glucoside (Glc $\beta \mathrm{OMe}$ ), and levoglucosan (LG) after the pyrolysis at $200,300,400$, and $500^{\circ} \mathrm{C}$ in the gas phase (residence times: $1.2-2.0 \mathrm{~s}, \mathrm{~N}_{2}$ flow $400 \mathrm{~mL} \mathrm{~min}^{-1}$ ). Filled circles methylglyoxal; filled triangles formaldehyde; filled squares glycolaldehyde; open circles glyoxal; open triangles acetaldehyde; open squares formic acid

phase. Extensive network of hydrogen bonding in the molten methyl glucosides may inhibit the proper association of the molecules forming TSs.

Several TSs can be drawn for the concerted mechanisms of gaseous LG (Fig. 8), but the complete recovery of the LG in the temperature range of $200-400{ }^{\circ} \mathrm{C}$ indicates that these reactions did not proceed unlike methyl glucosides. The instability of these TSs due to the steric effects of the bicyclic ring of LG would be an acceptable reason, and any TSs have not been identified, despite the computational trials of the theoretical calculations. 1,3-anhydroglucopyranose and 1,2;1,6-anhydroglucose obtained from TSs (A) and (C) would be unstable because of the inclusion of a sterically

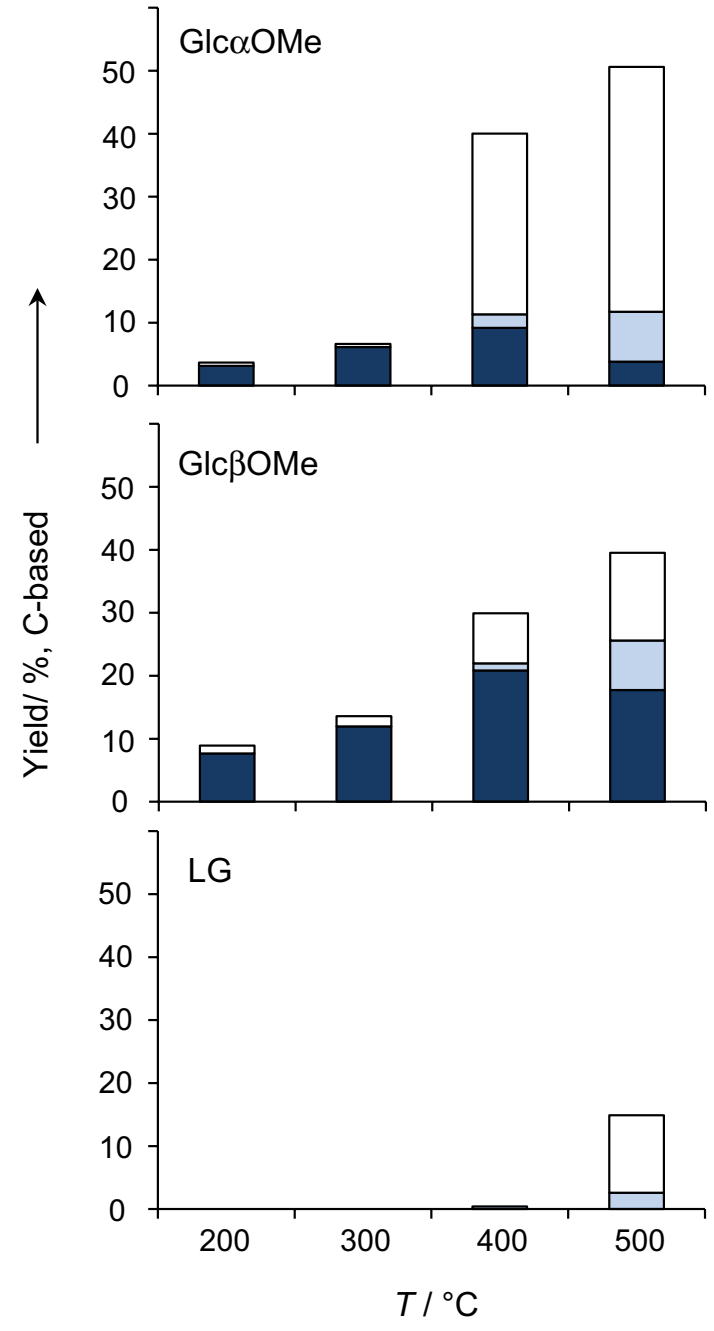

Fig. 6 Yields of levoglucosan (LG; except for the case of LG pyrolysis), fragmentation products, and gas/unidentified products from methyl $\alpha$-glucoside (Glc $\alpha \mathrm{OMe})$, methyl $\beta$-glucoside (Glc $\beta \mathrm{OMe})$, and LG after the pyrolysis at $200,300,400$, and $500^{\circ} \mathrm{C}$ in the gas phase (residence times 1.2-2.0 s, $\mathrm{N}_{2}$ flow $400 \mathrm{~mL} \mathrm{~min}^{-1}$ ). White bars gas/ unidentified products; light shaded bars fragmentation products; dark shaded bars LG

hindered four-membered ring and a bicyclic acetal system with a three membered epoxide ring, respectively.

\section{Fragmentation}

Radical-chain mechanisms are postulated for fragmentation of gaseous LG instead of heterolysis reactions from the kinetic data [12]. We discussed the different fragmentation reactivities $(\mathrm{Glc} \alpha \mathrm{OMe}>\mathrm{Glc} \beta \mathrm{OMe}>\mathrm{LG})$ in terms of the reactivities of the $\mathrm{C}$ - and $\mathrm{O}$-centered radicals, which are formed through hydrogen abstractions by radical species from $\mathrm{C}-\mathrm{H}$ and $\mathrm{O}-\mathrm{H}$ groups, respectively. Although the selectivity of the hydrogen abstraction during pyrolysis is unclear, 1-C, 6-C, and 6-O radicals shown in Fig. 9 


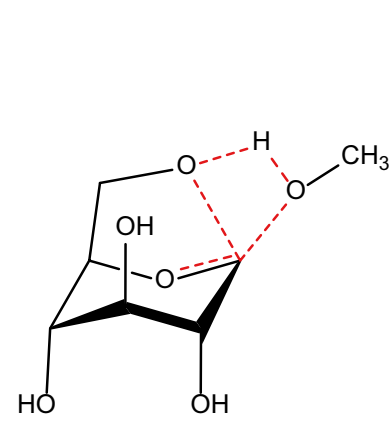

Unimolecular

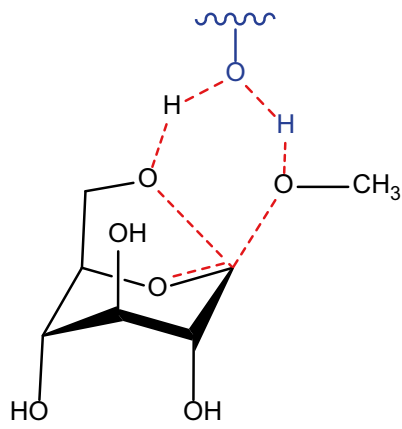

Bimolecular
Fig. 7 Uni- and bimolecular concerted mechanisms proposed by Hosoya et al. for the conversion from methyl $\beta$-glucoside to levoglucosan

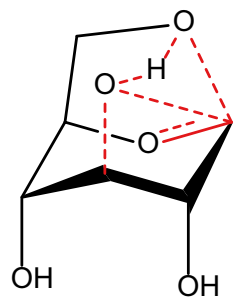

(A)

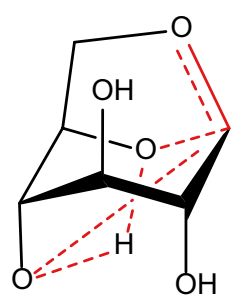

(B)

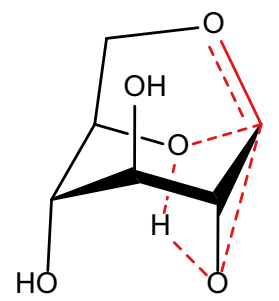

(C)

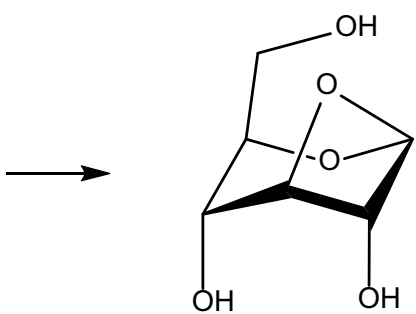

1,3-Anhydroglucopyranose

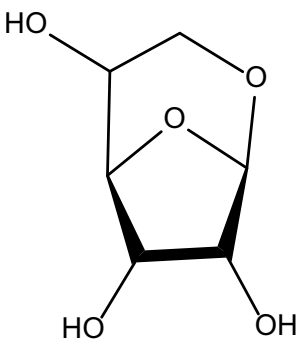

AGF

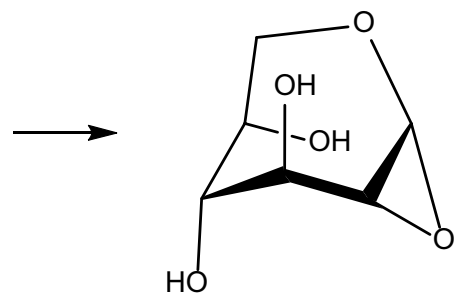

1,2;1,6-Anhydroglucose
Fig. 8 Transition states of the unimolecular concerted mechanisms for levoglucosan

were considered, because reactivities of these radicals are expected to be different between methyl glucosides and LG. Radical-type 6-O cannot be formed from LG.
To cleave the $\mathrm{C}-\mathrm{C}$ and $\mathrm{C}-\mathrm{O}$ bonds from radicals through $\beta$-scission reactions, these bonds must be in the same plane with the radical $p$ orbitals [48]. The bonds that can be cleaved were limited, as shown with the red bold lines in Fig. 9. Although several $\beta$-scission reactions can occur for the radicals from Glc $\alpha \mathrm{OMe}$ and Glc $\beta \mathrm{OMe}$, no bonds are cleaved from the LG radicals because of the steric effects of bicyclic ring. Thus, these LG radicals may be stabilized as LG by the abstraction of hydrogen from other molecules.

Among the postulated $\beta$-scission reactions in Fig. 9, the 1-C radicals produce vinyl ethers $\mathrm{A}$ and $\mathrm{B}$ with different oxidation states at $\mathrm{C}_{2}$ (Fig. 10), and they show different bond dissociation energies of the $\mathrm{C}_{5}-\mathrm{O}$ bonds, which were calculated as $35.9 \mathrm{kcal} \mathrm{mol}^{-1}$ for $\mathrm{A}$ from the $\alpha$-anomer and $48.0 \mathrm{kcal} \mathrm{mol}^{-1}$ for B from the $\beta$-anomer. For fragmentation of LG, double bond formation to produce vinyl ether and conjugated carbonyl structures is suggested to promote the fragmentation reactions through forming lower bond dissociation energy bonds, which result in cleaving homolytically to form pairs of radicals to accelerate the radicalchain reactions [12]. Thus, this efficiency is expected to be greater for Glc $\alpha \mathrm{OMe}$, which reasonably explains the fragmentation reactivity: Glc $\alpha \mathrm{OMe}>$ Glc $\beta \mathrm{OMe}$.

Using the reactivity of gaseous glyceraldehyde as a model of LG degradation intermediates compared with that of glycerol, we reported that the introduction of $\mathrm{C}=\mathrm{O}$ to polyalcohol significantly accelerated the fragmentation reactions by the progression of retro-aldol fragmentation and dehydration reactions [30]. Dehydration reaction is accelerated by the $\mathrm{C}=\mathrm{O}$ group, because the $\mathrm{C}=\mathrm{O}$ group increases the acidity of the adjacent $\mathrm{C}-\mathrm{H}$ group.

Fragmentation pathways via the 6-C and 6-O radicals formed from GlcoOMe and Glc $\beta O M e$ are provisionally considered as illustrated in Fig. 11, although the pyrolysis reactions are considered to be more complex. A retro-aldol fragmentation via a six-membered TS (calculated activation energy: $36.2 \mathrm{kcal} \mathrm{mol}^{-1}$ for GlcoOMe) would proceed for the $\mathrm{C}_{6}=\mathrm{O}$ intermediate to form intermediate $\mathbf{1}$, which is further fragmented into GA and $\mathbf{2}$ by an additional retroaldol fragmentation. Compound $\mathbf{2}$ with a weak vinyl ether bond would fragment further, which results in the formation of GO, GA and methyl radical. Alternatively, intermediate 1 would dehydrate to form $\mathbf{3}$ with a weak vinyl ether bond that is attached to a conjugated $\mathrm{C}=\mathrm{O}$, which is cleaved homolytically to GO, GA, along with radical 4. This radical can be converted further into MeGO and CO. Consequently, these postulated pathways reasonably explain the formation of the major fragmentation products, i.e., MeGO, GA, and GO, from the gaseous methyl glucosides at $>400{ }^{\circ} \mathrm{C}$. Fald would be formed from the fragmentation of GA. These reactions are not expected for $\mathrm{LG}$ with the $\mathrm{C}_{1}-\mathrm{O}-\mathrm{C}_{6}$ linkage. 


\section{Glc $\alpha \mathrm{OMe}$}

$1-\mathrm{C}$

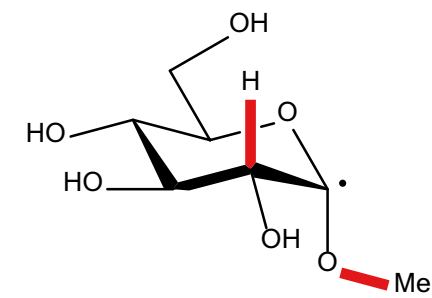

$6-C$
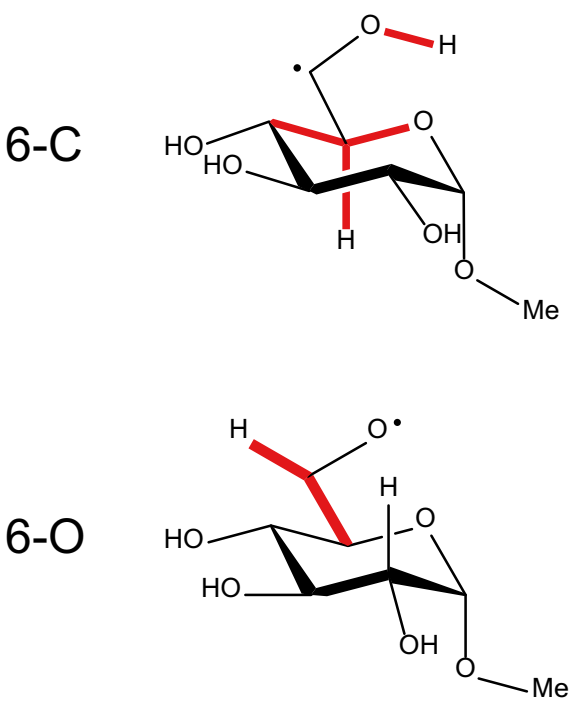

GlçOMe<smiles>CO[C@H]1O[C@@H](CO)[C@@H](O)[C@H](O)[C@H]1O</smiles><smiles>CO[C@H]1O[C@H](CO)[C@@H](O)[C@H](O)[C@H]1O</smiles><smiles>CO[C@H]1O[C@@H](C=C[O])[C@@H](O)[C@H]1O</smiles>

LG
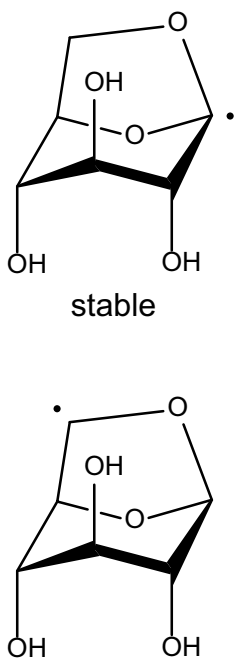

stable

Fig. 9 Cleavable linkages (red bold lines) through $\beta$-elimination for C- and O-centered radicals from methyl $\alpha$-glucoside (Glc $\alpha \mathrm{OMe}$ ), methyl $\beta$-glucoside Glc $\beta \mathrm{OMe}$, and levoglucosan (LG)

Fig. 10 Vinyl ethers that can be formed through $\beta$-scission reactions of the 1-C radicals from methyl $\alpha$-glucoside (Glc $\alpha \mathrm{OMe})$ and methyl $\beta$-glucoside

$(\mathrm{Glc} \beta \mathrm{OMe}$ ) along with the bond dissociation energies of the vinyl ether $\mathrm{C}-\mathrm{O}$ bonds

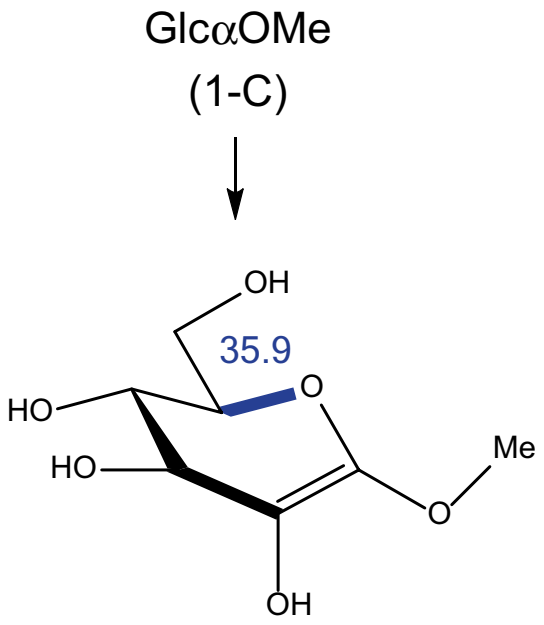

(A)
Glc $\beta O M e$

$(1-C)$
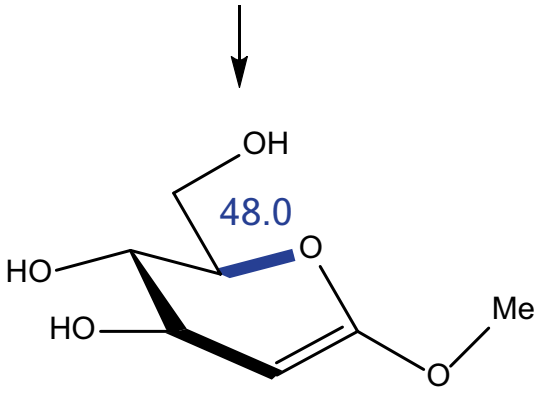

(B)

kcal mol${ }^{-1}$ 


\section{Glc $\alpha$ OMe 6-C, 6-O \\ GIc $\beta O M e$ radicals}
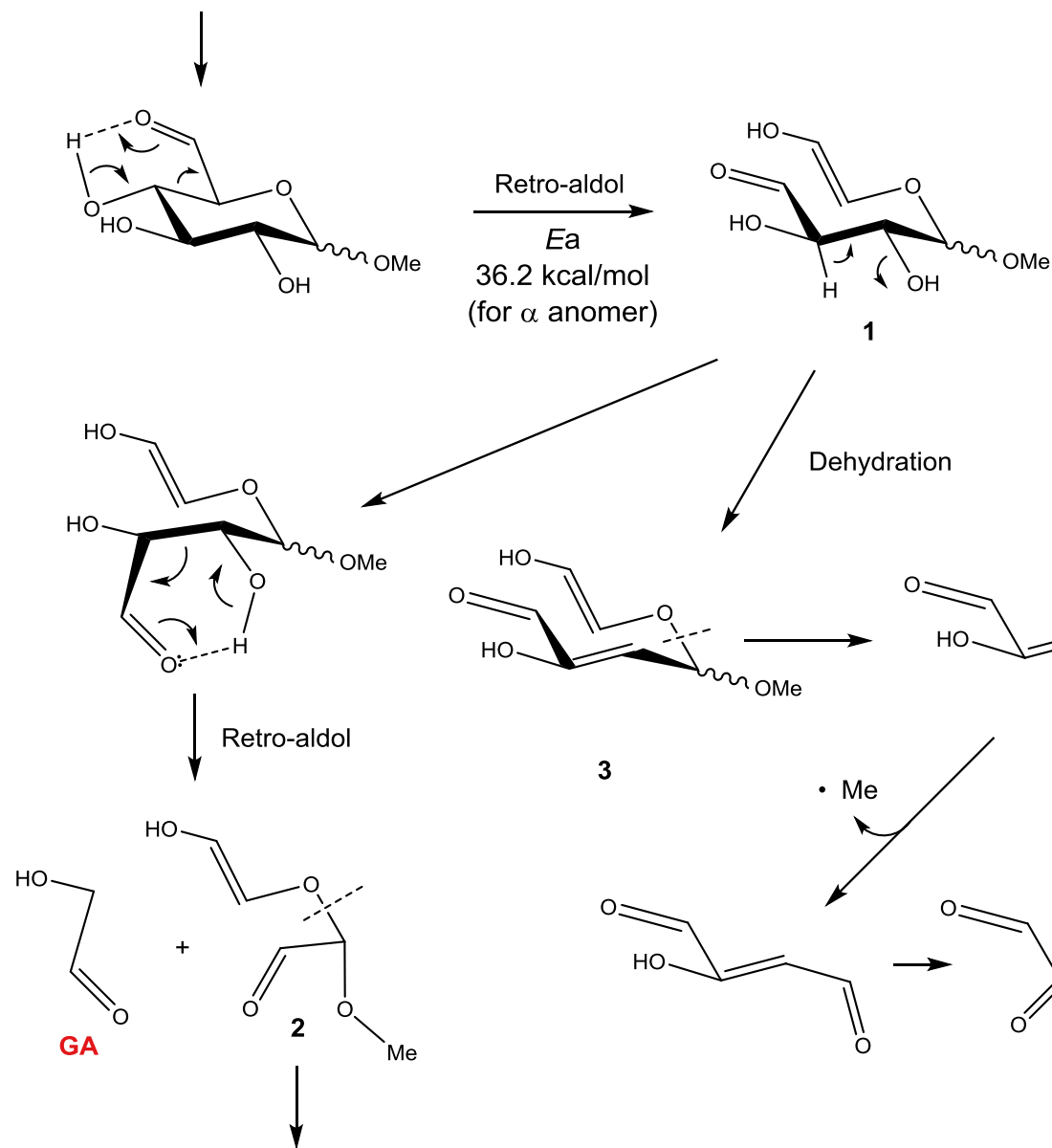

Dehydration

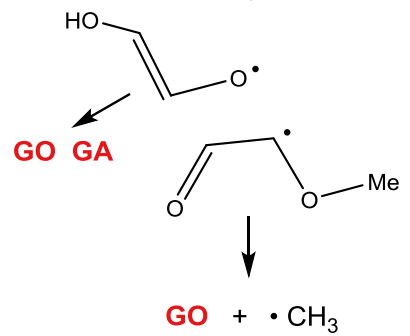

3
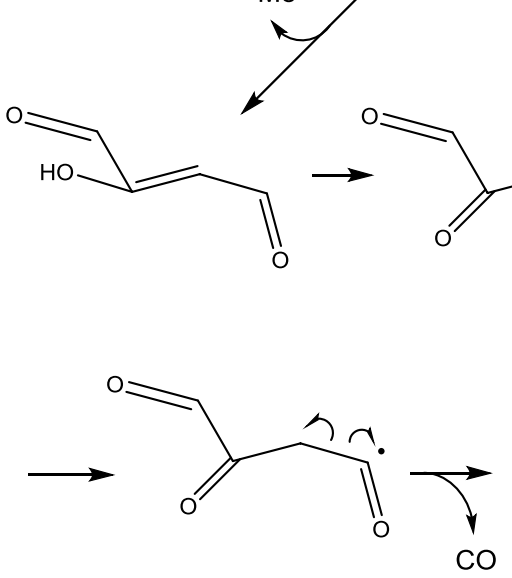

4<smiles>CO[C@H](C=C(O)C=O)CCO</smiles>

GO GA

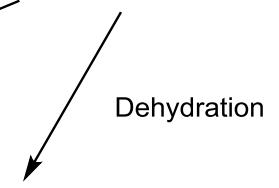

Fig. 11 Postulated fragmentation pathways for the $\mathrm{C}_{6}=\mathrm{O}$ intermediate formed from the 6-C and 6-O radicals of methyl $\alpha$-glucoside (Glc $\alpha \mathrm{OMe}$ ) and methyl $\beta$-glucoside (Glc $\beta \mathrm{OMe}$ ), with retro-aldol fragmentation and dehydration as key reactions

Radical-chain reactions via abstraction of hydrogens of more reactive (weaker) $\mathrm{C}-\mathrm{H}$ and $\mathrm{O}-\mathrm{H}$ bonds of allylic and vinyl alcohol structures would also proceed from the intermediates shown in Fig. 11.

\section{Roles of molten- and gas-phase reactions in the pyrolysis of methyl glucosides}

The product compositions from the gaseous methyl glucosides were different from those of the pyrolysis including molten-phase reactions. These features provide insights into the roles of molten- and gas-phase reactions during the pyrolysis of methyl glucoside (GlcOMe) as summarized in Fig. 12.

Along with AGF, no furans (furfural and 5-HMF) were obtained from the pyrolysis of GlcOMe (gas) and LG (gas). Thus, the transformation from the pyranose to fivemembered heterocyclic rings does not effectively proceed in the gas-phase pyrolysis. Hence, AGF and furan 
Fig. 12 Proposed mechanism for the pyrolysis of molten methyl glucoside (GlcOMe), focusing on the molten- and gas-phase reactions

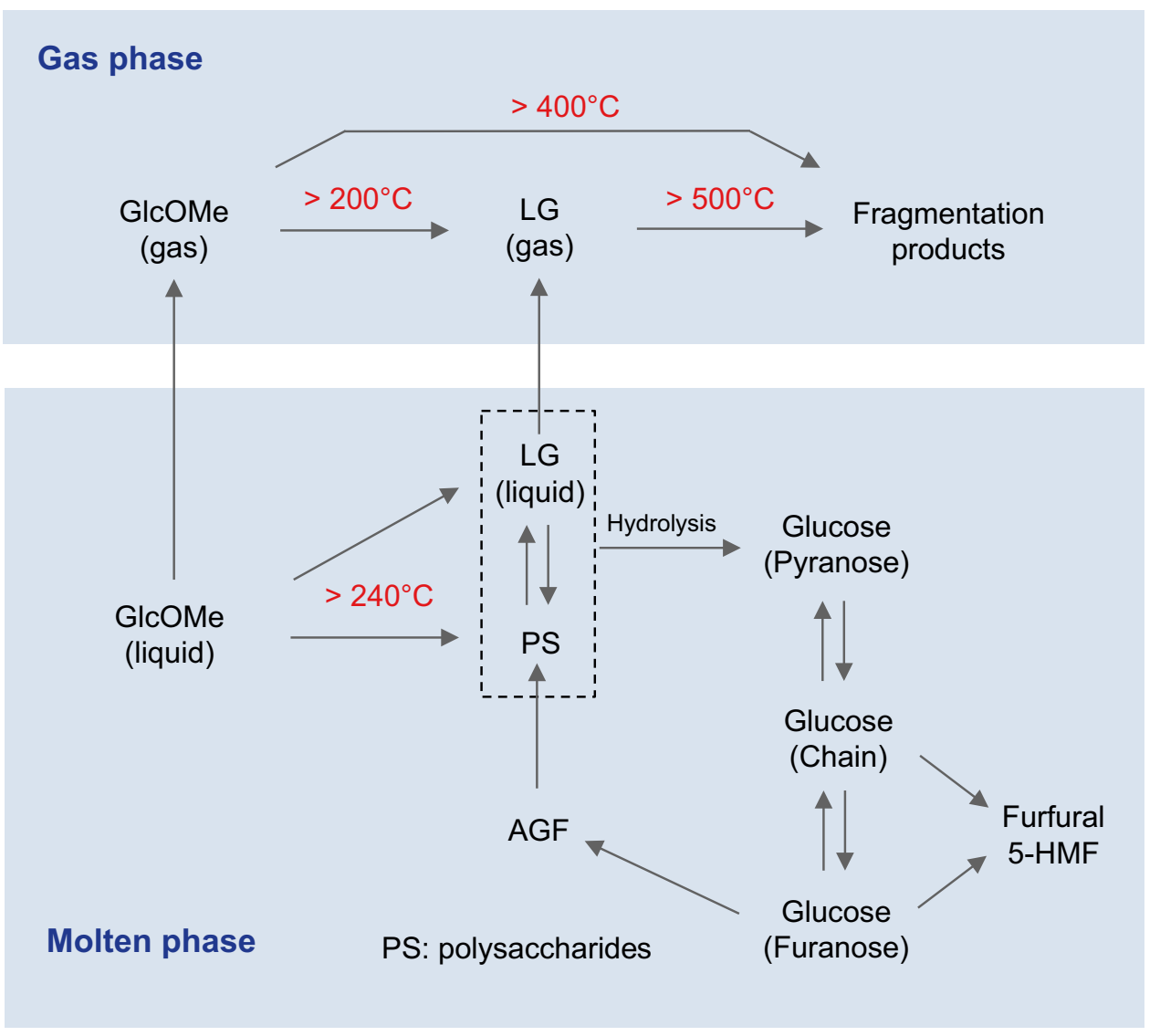

formations probably originate from the molten-phase reactions prior to evaporation into the gas phase.

The pyran-to-furan ring transformation is possible via the chain structure of glucose, which may form by hydrolysis reactions. The yields of AGF and furans are reported to change depending on the degree of polymerization, i.e., content of reducing end [26-29], which can be converted into the chain structure. For example, Gardiner [26] reported the AGF yield decreased with the increase in the degree of polymerization: glucose $(10.9 \%)>$ cellobiose $(2.8 \%)>$ cellulose $(1.5 \%)$, and Kato [49] reported the same tendency for the formation of furfural: glucose $(11.7 \%)>$ cellobiose $(7.7 \%)>$ cellulose $(3.7 \%)$. These reported results support the above hypothesis.

Hydrolysis of cellulose is reported to proceed effectively during the pyrolysis in a sealed reactor [50, 51]. Recent studies [52-54] also reported that the hydrolysis reactions proceed in a quasi-sealed space formed in the cell wall of cellulose and molten glycosides even during the pyrolysis with open-top reactors. Thus, hydrolysis by the produced water would proceed during the moltenphase pyrolysis of methyl glucosides and LG to form glucose, which is further converted into AGF, furfural, and 5-HMF, probably via the chain and furanose structures.
The evaporation process of GlcOMe and the product LG is expected to compete with the molten-phase reactions forming polysaccharides, AGF, furfural, and 5-HMF. The GlcOMe (gas) undergoes simpler reactions in the gas phase, i.e., transglycosylation to form LG (gas) and fragmentation. The greater stability of LG (gas) may be a reason why large amounts of $L G$ are produced from the pyrolysis of GlcOMe, cellulose, and other glucosebased carbohydrates.

\section{Conclusions}

Pyrolytic reactivities of GlcOMe were studied only in the gas phase for the first time and compared with that of LG. The following results were obtained:

1. Unlike $\mathrm{LG}$, phase transition from molten to gas phases increases the GlcOMe reactivity, and the gaseous GlcOMe selectively produces LG at low pyrolysis temperatures $\left(200\right.$ and $\left.300^{\circ} \mathrm{C}\right)$, at which LG is completely stable. 
2. Selective transglycosylation of GlcOMe can be explained with the uni- and bimolecular concerted heterolysis mechanisms.

3. The greater stability of LG for transglycosylation is explained by the steric effects of the bicyclic ring system.

4. Fragmentation of $\mathrm{GlcOMe}$ starts at $400^{\circ} \mathrm{C}$, although higher temperatures $>500^{\circ} \mathrm{C}$ are required for $\mathrm{LG}$.

5. Difference in fragmentation reactivity (Glc $\alpha \mathrm{OMe}>\mathrm{Glc} \beta \mathrm{OMe})$ can be explained in terms of the radical-chain reactivity.

6. The AGF yields are low and no furans are obtained from the gaseous GlcOMe. These compounds are suggested to originate mainly from the molten-phase pyrolysis reactions.

7. Unconventional stability of LG against transglycosylation and fragmentation reactions is suggested to be a reason for the formation of large amounts of LG from the pyrolysis of carbohydrates including GlcOMe and cellulose.

8. These findings provide insights for the efficient production of LG from glucose-based carbohydrates and efficient gasification of cellulosic biomass.

Acknowledgements This research was partly conducted using the supercomputer system of the Academic Center for Computing and Media Studies, Kyoto University. This work was supported by the Grants-in-Aid for Scientific Research (B) (Grant Number 24380095, 2012.4-2016.3) from the Ministry of Education, Culture, Sports, Science and Technology, Japan, and JSPS KAKENHI Grant Number $16 \mathrm{H} 04954$.

\section{References}

1. Shafizadeh F, Furneaux RH, Cochran TG, Scholl JP, Sakai Y (1979) Production of levoglucosan and glucose from pyrolysis of cellulosic materials. J Appl Polym Sci 23:3525-3539

2. Kwon GJ, Kim DY, Kimura S, Kuga S (2007) Rapid-cooling, continuous-feed pyrolyzer for biomass processing. Preparation of levoglucosan from cellulose and starch. J Anal Appl Pyrolysis 80:1-5

3. Hosoya T, Kawamoto H, Saka S (2008) Different pyrolytic pathways of levoglucosan in vapor- and liquid/solid-phases. J Anal Appl Pyrolysis 83:64-70

4. Fukutome A, Kawamoto H, Saka S (2014) Gas- and coke-forming reactivities of cellulose-derived tar components under nitrogen and oxygen/nitrogen. J Anal Appl Pyrolysis 108:98-108

5. Kawamoto H, Murayama M, Saka S (2003) Pyrolysis behavior of levoglucosan as an intermediate in cellulose pyrolysis: polymerization into polysaccharide as a key reaction to carbonized product formation. J Wood Sci 49:469-473

6. Bai X, Johnston P, Brown RC (2013) An experimental study of the competing processes of evaporation and polymerization of levoglucosan in cellulose pyrolysis. J Anal Appl Pyrolysis 99:130-136

7. Kawamoto H, Morisaki H, Saka S (2009) Secondary decomposition of levoglucosan in pyrolytic production from cellulosic biomass. J Anal Appl Pyrolysis 85:247-251
8. Shin EJ, Nimlos MR, Evans RJ (2001) Kinetic analysis of the gas-phase pyrolysis of carbohydrates. Fuel 80:1697-1709

9. Fukutome A, Kawamoto H, Saka S (2015) Processes forming gas, tar and coke in cellulose gasification from gas-phase reactions of levoglucosan as intermediate. ChemSusChem 8:2240-2249

10. Fukutome A, Kawamoto H, Saka S (2016) Molecular mechanisms for the gas-phase conversion of intermediates during cellulose gasification under nitrogen and oxygen/nitrogen. Chem Ind Chem Eng Q 22:343-353

11. Pictet A (1918) On the transformation of levoglucoscine to dextrine. Helv Chim Acta 1:226-230

12. Fukutome A, Kawamoto H, Saka S (2017) Kinetics and molecular mechanisms for the gas-phase degradation of levoglucosan as a cellulose gasification intermediate. J Anal Appl Pyrolysis. doi:10.1016/j.jaap.2016.12.010

13. Hosoya T, Kawamoto H, Saka S (2007) Pyrolysis behaviors of wood and its constituent polymers at gasification temperature. $\mathrm{J}$ Anal Appl Pyrolysis 78:328-336

14. Hosoya T, Kawamoto H, Saka S (2006) Thermal stabilization of levoglucosan in aromatic substances. Carbohydr Res 341:2293-2297

15. Kawamoto H, Hosoya T, Ueno Y, Shoji T, Saka S (2014) Thermal stabilization and decomposition of simple glycosides in the presence of aromatic substances in closed ampoules. Role of $\mathrm{OH} \cdots \pi$ hydrogen bonding. J Anal Appl Pyrolysis 109:41-46

16. Matsuoka S, Kawamoto H, Saka S (2012) Retro-aldol-type fragmentation of reducing sugars preferentially occurring in polyether at high temperature. Role of the ether oxygen as a base catalyst. J Anal Appl Pyrolysis 93:24-32

17. Kawamoto H, Ueno Y, Saka S (2013) Thermal reactivities of non-reducing sugars in polyether -Role of intermolecular hydrogen bondings in pyrolysis. J Anal Appl Pyrolysis 103:287-292

18. Shafizadeh F, Fu LY (1973) Pyrolysis of cellulose. Carbohydr Res 29:113-122

19. Wolfrom ML, Thompson A, Ward RB (1959) The composition of pyrodextrins 2. Thermal polymerization of levoglucosan. J Am Chem Soc 81:4623-4625

20. Wolfrom ML, Ward RB, Horton D, Moore RH, Thompson A (1961) Composition of pyrodextrins 3. Thermal polymerization of levoglucosan. J Org Chem 26:4617-4620

21. Hosoya T, Nakao Y, Sato H, Kawamoto H, Sakaki S (2009) Thermal degradation of methyl beta-D-glucoside. A theoretical study of plausible reaction mechanisms. J Org Chem 74:6891-6894

22. Seshadri V, Westmoreland PR (2012) Concerted reactions and mechanism of glucose pyrolysis and implications for cellulose kinetics. J Phys Chem A 116:11997-12013

23. Mayes HB, Broadbelt LJ (2012) Unraveling the reactions that unravel cellulose. J Phys Chem A 116:7098-7106

24. Hosoya T, Sakaki S (2013) Levoglucosan formation from crystalline cellulose: importance of a hydrogen bonding network in the reaction. ChemSusChem 6:2356-2368

25. Frisch MJ, Trucks GW, Schlegel HB, Scuseria GE, Robb MA, Cheeseman JR, Scalmani G, Barone V, Mennucci B, Petersson GA, Nakatsuji H, Caricato M, Li X, Hratchian HP, Izmaylov AF, Bloino J, Zheng G, Sonnenberg JL, Hada M, Ehara M, Toyota K, Fukuda R, Hasegawa J, Ishida M, Nakajima T, Honda Y, Kitao O, Nakai H, Vreven T, Montgomery JAJ, Peralta JE, Ogliaro F, Bearpark M, Heyd JJ, Brothers E, Kudin KN, Staroverov VN, Kobayashi R, Normand J, Raghavachari K, Rendell A, Burant JC, Iyengar SS, Tomasi J, Cossi M, Rega N, Millam JM, Klene M, Knox JE, Cross JB, Bakken V, Adamo C, Jaramillo J, Gomperts R, Stratmann RE, Yazyev O, Austin AJ, Cammi R, Pomelli C, Ochterski JW, Martin RL, Morokuma K, Zakrzewski VG, Voth GA, Salvador P, Dannenberg JJ, Dapprich S, Daniels 
AD, Farkas O, Foresman JB, Ortiz JV, Cioslowski J, Fox DJ (2009) Gaussian 09, Revision A.02. Gaussian Inc., Wallingford

26. Gardiner D (1966) Pyrolysis of some hexoses and derived di- triand poly-saccharides. J Chem Soc C Org, 1473-1476

27. Sanders EB, Goldsmith AI, Seeman JI (2003) A model that distinguishes the pyrolysis of D-glucose, D-fructose, and sucrose from that of cellulose. Application to the understanding of cigarette smoke formation. J Anal Appl Pyrolysis 66:29-50

28. Patwardhan PR, Satrio JA, Brown RC, Shanks BH (2009) Product distribution from fast pyrolysis of glucose-based carbohydrates. J Anal Appl Pyrolysis 86:323-330

29. Mettler MS, Paulsen AD, Vlachos DG, Dauenhauer PJ (2012) The chain length effect in pyrolysis: bridging the gap between glucose and cellulose. Green Chem 14:1284-2288

30. Fukutome A, Kawamoto H, Saka S (2016) Gas-phase reactions of glyceraldehyde and 1,3-dihydroxyacetone as a model for levoglucosan conversion during biomass gasification. ChemSusChem 9:703-712

31. Zhang W, Du B, Qin Z (2014) Catalytic effect of water, formic acid, or sulfuric acid on the reaction of formaldehyde with $\mathrm{OH}$ radicals. J Phys Chem A 118:4797-4807

32. Kaur R, Vikas (2016) Exploring the role of a single water molecule in the tropospheric reaction of glycolaldehyde with an $\mathrm{OH}$ radical: a mechanistic and kinetics study. RSC Adv 6:29080-29098

33. Anglada JM, Gonzalez J (2009) Different catalytic effects of a single water molecule: the gas-phase reaction of formic acid with hydroxyl radical in water vapor. ChemPhysChem 10:3034-3045

34. Vöhringer-Martinez E, Hansmann B, Hernandez H, Francisco JS, Troe J, Abel B (2007) Water catalysis of a radical-molecule gas-phase reaction. Science 315:497-501

35. Curtiss LA, Blander M (1988) Thermodynamic properties of gas-phase hydrogen-bonded complexes. Chem Rev 88:827-841

36. Matsumoto M, Yasuoka K (1994) Evaporation and condensation at a liquid surface. II. Methanol. J Chem Phys 101:7912-7917

37. Faubel M, Kisters Th (1989) Non-equilibrium molecular evaporation of carboxylic acid dimers. Nature 339:527-529

38. Weltner W Jr, pitzer KS (1951) Methyl alcohol: the entropy, heat capacity and polymerization equilibria in the vapor, and potential barrier to internal rotation. J Am Chem Soc 73:2606-2610

39. Fletcher AN (1971) Self-association of methanol vapor. Evidence for dimers and tetramers. J Phys Chem 75:1808-1814

40. Cheam V, Farnham SB, Christian SD (1970) Vapor phase association of methanol. Vapor density evidence for trimer formation. J Phys Chem 74:4157-4159
41. Renner TA, Kucera GH, Blander M (1977) A study of hydrogen bonding in methanol vapor by measurement of thermal conductivity. J Chem Phys 66:177-184

42. Mitev VM, Stefanov B, Ivanov LM, Georgiev GM (1985) Infrared absorption spectra of methanol vapor: dimer and tetramer contributions. J Mol Struct 129:11-15

43. Dixon JR, George WO, Hossain MF, Lewis R, Price JM (1997) Hydrogen-bonded forms of methanol IR spectra and ab initio calculations. J Chem Soc Faraday Trans 93:3611-3618

44. Huisken F, Stemmler M (1992) Infrared molecular beam depletion spectroscopy of size-selected methanol clusters. Z Phys D Atoms Mol Clusters 24:277-287

45. Shi YJ, Consta S, Das AK, Mallik B, Lacey D, Lipson RH (2002) A $118 \mathrm{~nm}$ vacuum ultraviolet laser/time-of-flight mass spectroscopic study of methanol and ethanol clusters in the vapor phase. J Chem Phys 116:6990-6999

46. Hansen JC, Francisco JS (2002) Radical-molecule complexes: changing our perspective on the molecular mechanisms of radical-molecule reactions and their impact on atmospheric chemistry. ChemPhysChem 3:833-840

47. Alvarez-Idaboy JR, Mora-Diez N, Boyd RJ, Vivier-Bunge A (2001) On the importance of prereactive complexes in moleculeradical reactions: hydrogen abstraction from aldehydes by $\mathrm{OH}$. J Am Chem Soc 123:2018-2024

48. Parsons AF (2000) Radical reactions. In: An introduction to free radical chemistry. Blackwell Science Ltd, London, p 72

49. Kato K (1967) Pyrolysis of cellulose 3. Comparative studies of volatile compounds from pyrolysates of cellulose and its related compounds. Agric Biol Chem 31:657-663

50. Mok WSL, Antal MJ, Szabo P, Varhegyi G, Zelei B (1992) Formation of charcoal from biomass in a sealed reactor. Ind Eng Chem Res 31:1162-1166

51. Varhegyi G, Szabo P, Mok WSL, Antal MJ (1993) Kinetics of the thermal-decomposition of cellulose in sealed vessels at elevated pressures-effects of the presence of water on the reactionmechanism. J Anal Appl Pyrolysis 26:159-174

52. Yu Y, Liu D, Wu H (2012) Characterization of water-soluble intermediates from slow pyrolysis of cellulose at low temperatures. Energy Fuels 26:7331-7339

53. Matsuoka S, Kawamoto H, Saka S (2014) What is active cellulose in pyrolysis? An approach based on reactivity of cellulose reducing end. J Anal Appl Pyrolysis 106:138-146

54. Matsuoka S, Kawamoto H, Saka S (2016) Reactivity of cellulose reducing end in pyrolysis as studied by methyl glucoside-impregnation. Carbohydr Res 420:46-50 